\title{
ISOLATION AND PURIFICATION OF COMPLEX II FROM PROTEUS MIRABILIS STRAIN ATCC 29245
}

\author{
Khadija Shabbiri $^{1 *}$; Waqar Ahmad ${ }^{1}$; Quratulain Syed ${ }^{2}$; Ahmad Adnan ${ }^{1}$ \\ ${ }^{1}$ GC University, Lahore, Pakistan; ${ }^{2}$ Pakistan Council of Scientific and Industrial Research Labs Complex, Lahore, Pakistan.
}

Submitted: May 21, 2009; Approved: March 16, 2010.

\begin{abstract}
A respiratory complex was isolated from plasma membrane of pathogenic Proteus mirabilis strain ATCC 29245. It was identified as complex II consisting of succinate:quinone oxidoreductase (EC 1.3.5.1) containing single heme $\mathrm{b}$. The complex II was purified by ion-exchange chromatography and gel filtration. The molecular weight of purified complex was $116.5 \mathrm{kDa}$ and it was composed of three subunits with molecular weights of $19 \mathrm{kDa}, 29 \mathrm{kDa}$ and $68.5 \mathrm{kDa}$. The complex II contained $9.5 \mathrm{nmoles}$ of cytochrome b per $\mathrm{mg}$ protein. Heme staining indicated that the $19 \mathrm{kDa}$ subunit was cytochrome $\mathrm{b}$. Its reduced form showed absorptions peaks at 557.0, 524.8 and $424.4 \mathrm{~nm}$. The $\alpha$-band was shifted from $557.0 \mathrm{~nm}$ to 556.8 $\mathrm{nm}$ in pyridine ferrohemochrome spectrum. The succinate: quinone oxidoreductase activity was found to be high in this microorganism.
\end{abstract}

Key words: Proteus mirabilis, complex II, cytochrome b

\section{INTRODUCTION}

Proteus mirabilis belongs to family Enterobacteriaceae and is facultative anaerobic, rod shaped, and gram negative bacterium (14). It is mainly found in GI tract, soil, infections of bladder, lung, urinary tract and wounds. It infects and persists for a long period of time (26). It also causes pneumonia, chills, fever, cough and chest pain $(4,12,27)$.

In bacterial cells, the generation of energy in the form of adenosine triphosphate (ATP) is mainly motivated by the activity of respiratory chain enzymes of inner plasma membrane (5). The respiratory chain of bacteria usually composed of enzyme complexes I to IV, ubiquinone, cytochromes, and ATP synthase (complex V), transfers electrons from NADH and succinate at one end to molecular oxygen at the other (2). Van Wielink et al. (22) observed the presence of cytochrome $b$, al and $d$ in spectral investigation of the plasmic membrane of Proteus mirabilis. Van Wielink et al. also (20) characterized the presence of cytochrome b and $c$ in plasmic membranes of Proteus mirabilis by means of $77 \mathrm{~K}$ spectra in both aerobic and anaerobic conditions. The function of cytochrome b was investigated in Proteus mirabilis (21) revealed the presence of cytochrome $\mathrm{b}$ in $\mathrm{Q}$ or $\mathrm{b}$-cycle between the two HQNO inhibition sites. Thus a few types of respiratory components of Proteus mirabilis have been studied with their enzymatic and structural features. However the presence of the succinate: quinine oxidoreductase (complex II) of Proteus mirabilis has not so far been completely studied.

Complex II of the bacterial electron transport chain is of special interest. It functions as a dehydrogenase in the respiratory system and plays an important role in the tricarboxylic acid cycle (TAC) (17). This membrane associated complex catalyses the oxidation of succinate to fumarate and reduce ubiquinone to ubiquinol, and has been characterized in bacteria and heterophilic eukaryotes (19). Complex II (succinate:quinone oxidoreductase) of aerobic respiratory chain 
oxidizes succinate to fumarate and passes electrons directly into the quinone pool. It serves as the only direct link between activity in the citric acid cycle and electron transport in the membrane (1). Membrane-bound succinate dehydrogenases (succinate:quinone reductases, $\mathrm{SQR}$ ) couples the oxidation of succinate to fumarate to the reduction of quinone to quinol and also catalyzes the reverse reaction. SQR (respiratory complex II) is involved in aerobic metabolism as part of the citric acid cycle and of the aerobic respiratory chain (11). Iron sulfur clusters and flavin adenine dinucleotide (FAD) are located in the water soluble moiety, while cytochrome b is present in membrane-bound moiety. The purified succinate quinine oxidoreductase from Bacillus subtilis contains two hemes b and the other gram negative bacteria such as $E$. coli $(6,9)$ and $P$. denitrificans (15) contains one molecule of heme b per FAD which showed that cytochrome b was generally present with the association of succinate: quinine oxidoreductase.

In present study we report the isolation and purification of complex II found in the plasmic membrane of Proteus mirabilis strain ATCC 29245 and its activity in vitro.

\section{MATERIALS AND METHODS}

\section{Materials}

DEAE-Bio-Gel and Bio-Gel-P100 were purchased from Bio-Rad Pakistan. DEAE-Sephadex and Sodium succinate from Sigma, Triton-X100 from Acros (USA), Commassie Brilliant Blue dye from Fischer, DCPIP and Tris salt from Fluka and Pyridine and Sodium dithionite from BDH (U.K) and Nutrient Broth, Nutrient agar, Potassium dichromate, SDS and EDTA were purchased from Merck. All other chemicals used in this study were of the extra pure grade.

\section{Organism and culture conditions}

The gram -ve facultative bacterium Proteus mirabilis strain (ATCC 29245) was used in the present study. The strain was provided by PCSIR Laboratories Lahore, Pakistan. The bacterium was aerobically grown on nutrient medium (Merck) in conical flasks at $37^{\circ} \mathrm{C}$ on shaker $\left(\mathrm{C}_{24} \mathrm{KC}\right.$ Refrigerated
Incubator shaker USA) at $250 \mathrm{rpm}$. Growth of Proteus was studied after the regular interval of 2 hours by taking its optical density by spectrophotometer (CICIL/UV-Visible Spectrophotometer HitachiU-2001) at $595 \mathrm{~nm}$. The cultivation of Proteus mirabilis was performed in 200 liters of the above nutrient medium with a stainless steel fermenter of $500 \mathrm{~L}$ volume. The culture was harvested at the early exponential phase by centrifugation at $4000 \mathrm{rpm}$ for $25 \mathrm{~min}$ and suspended in 50mM Tris $\mathrm{HCl}$ buffer (pH: 8.4) containing 50mM EDTA.

\section{Purification of membrane bound complex- II}

Frozen cells (about $25 \mathrm{gm}$ in a centrifugally packed state) were suspended in $100 \mathrm{ml}$ of $50 \mathrm{mM}$ Tris $\mathrm{HCl}$ buffer $(\mathrm{pH}: 8.4)$ and $20 \mathrm{ml}$ of $50 \mathrm{mM}$ EDTA (buffer A). The suspension was sonicated with a sonic oscillator (Soniprep 150 SANYO UK) at 12-14 KHz for total period of 15 min with intervals of $1 \mathrm{~min}$ at $4^{\circ} \mathrm{C}$. After sonication the suspension was subjected to centrifuge by using centrifuge machine (HITACHI-CP $80 \mathrm{MX}$ ) at $15000 \mathrm{rpm}$ at $4^{\circ} \mathrm{C}$ for $15 \mathrm{~min}$. Supernatant contained membrane fraction and cytoplasmic fraction where as pellets were of unbroken cells. The supernatant then ultra centrifuged at $35000 \mathrm{rpm}$ and $4^{\circ} \mathrm{C}$ for $60 \mathrm{~min}$. The reddish pellet obtained was of cell membrane whereas the supernatant was of cytoplasm. Then cell membrane pellet was suspended in $25 \mathrm{ml}$ of 50mM Tris-HCl buffer ( $\mathrm{pH} 8.4$ ) with $2.5 \mathrm{ml}$ of 50mM EDTA and $4.2 \mathrm{ml}$ of $20 \%(\mathrm{wt} / \mathrm{vol})$ Triton-X 100 (with final concentration of detergent is $3 \%$ ). The resulting mixture was stirred using a magnetic stirrer for 1 hour to solubilize the total cell membrane proteins. This suspension was then ultracentrifuged at $45000 \mathrm{rpm}$ and $4^{\circ} \mathrm{C}$ for $45 \mathrm{~min}$. Reddish supernatant thus obtained was total membrane proteins and subjected to a first ion-exchange chromatography (Biologic LP System, BIO-RAD) on a DEAE-Sephadex column( 4.0 by 16.0 $\mathrm{cm})$ equilibrated with buffer A. The column was washed with $400 \mathrm{ml}$ of buffer A containing $1 \%$ of Triton X-100, then enzyme was eluted by using linear gradient solution of $600 \mathrm{ml}$ each of buffer A containing 1\% of Triton X-100 and buffer B containing $1 \%$ Triton $\mathrm{X}-100$ and $1.0 \mathrm{M} \mathrm{NaCl}$. The eluates having enzymatic activity were collected (BIO-RAD, Model 
2110 Fraction collector) and dialyzed against 1 liter of buffer A and then subjected to a second ion exchange chromatography on DEAE-Bio-Gel $(1.5$ by $8.0 \mathrm{~cm})$ equilibrated with buffer A. The adsorbed enzyme was eluted with a linear gradient of $\mathrm{NaCl}$ $(0-1.0 \mathrm{M} \mathrm{NaCl})$ produced in $600 \mathrm{ml}$ of buffer A containing $1 \%$ Triton X-100. Thus the fractions $30-34$ (5ml each) with the enzymatic activity as shown in (Figure 2) were collected and concentrated by lyophilization to an appropriate size and subjected to gel filtration with a Bio-Gel P-100 column equilibrated with $50 \mathrm{mM}$ Tris- $\mathrm{HCl}$ buffer ( $\mathrm{pH}: 8.4)$ containing $1 \%$ Triton $\mathrm{X}-100$ and $0.5 \mathrm{M} \mathrm{NaCl}$. The yellowish-red complex II fraction was collected and used as purified preparation.

\section{Spectroscopy}

Absorption spectra of respiratory proteins were studied by using a quartz cuvette with the CICIL/UV-Visible Spectrophotometer Hitachi U-2001 at room temperature in visible range. Cytochrome $\mathrm{b}$ from Proteus mirabilis strain ATCC 29245 was suspended in 50mM Tris- $\mathrm{HCl}$ (pH: 8.4) containing $1 \%$ Triton X-100. Cytochrome b was oxidized with $1 \mathrm{M}$ Potassium dichromate solution and reduced by adding few pellets of sodium dithionite. For obtaining ferrohemochrome spectra, the $0.7 \mathrm{~mL}$ enzyme was suspended in $0.5 \mathrm{~mL}$ of $0.2 \mathrm{~N}$ $\mathrm{NaOH}, 1.8 \mathrm{~mL}$ of distilled water and $0.5 \mathrm{ml}$ of pyridine and then reduced with a small amount (500mg)of sodium dithionite.

\section{Polyacrylamide Gel Electrophoresis}

Native polyacrylamide gel electrophoresis was performed in the presence of $0.4 \%$ Triton X-100 and Sodium dodecyl sulfate polyacrylamide gel electrophoresis (SDS-PAGE) was performed under denaturing conditions at room temperature by the method of Schagger and von Jagow (18). In the estimation of the apparent molecular weight by SDS-polyacrylamide gel electrophoresis, a set of protein markers (PAGE ruler prestained protein ladder, SM0671 Fermentas) with known molecular weights were used. The presence of cytochrome $b$ in the native gel was detected by heme staining reagent (3).

\section{Assay of Redox Activity}

Cytochrome $\mathrm{b}$ oxidoreductase activity was measured at room temperature spectrophotometrically (CICIL/UV-Visible Spectrophotometer. Hitachi U-2001) in time scanned mode. The oxidation of succinate to fumarate with concomitant transport of electron to DCPIP dye (which acts as electron accepter) was determined by monitoring the decrease in absorbance at $600 \mathrm{~nm}$ for $5 \mathrm{~min}$. The reaction mixture contained $9 \mu \mathrm{L}$ of $0.1 \mathrm{M}$ EDTA, $3 \mathrm{~mL}$ of $50 \mathrm{mM}$ Tris-HCl buffer ( $\mathrm{pH} 8.4$ ), $159 \mu \mathrm{L}$ of $1 \mathrm{mM}$ (dichlorophenolindophenol) DCPIP dye, and $60 \mu \mathrm{L}$ of $0.1 \mathrm{M}$ sodium succinate. Addition of the enzyme ( $40 \mu \mathrm{L}$ of Complex II) initiated the reaction.

\section{RESULTS}

\section{Growth profile of Proteus mirabilis strain ATCC 29245}

Growth profile of Proteus mirabilis showed that maximum growth could be achieved after 12-14 hours of incubation at $37^{\circ} \mathrm{C}$ (Fig.1). Biomass was collected after 12 hours of incubation to ensure maximum activity of complex II.

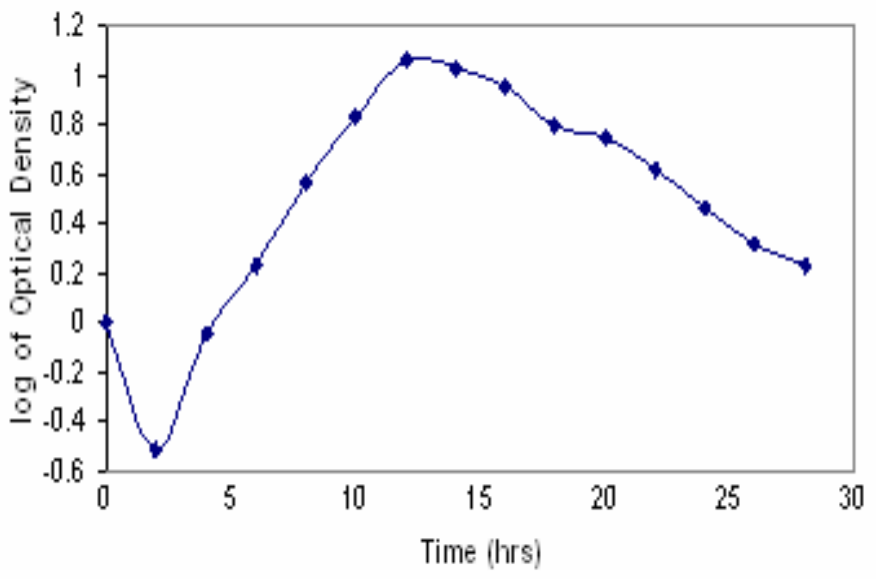

Figure 1. Growth profile of Proteus mirabilis strain ATCC 29245. It shows that maximum active biomass can be achieved in 12-14 hrs after incubation.

\section{Purification of Complex II from Proteus mirabilis strain ATCC 29245}

The membrane bound respiratory complex II was solublized with Triton X-100 and purified by ion-exchange chromatography and gel filtration. Purification factors and yields were shown in the Table 1. Purification was started with 
solublized membranes containing a total amount of $235 \mathrm{mg}$ of polyacrylamide gel electrophoresis (Native PAGE) since a protein and $310 \mathrm{nmol}$ of total heme $\mathrm{b}$. The final preparation single band was observed after heme staining. appeared to be homogenous as revealed by nondenaturing

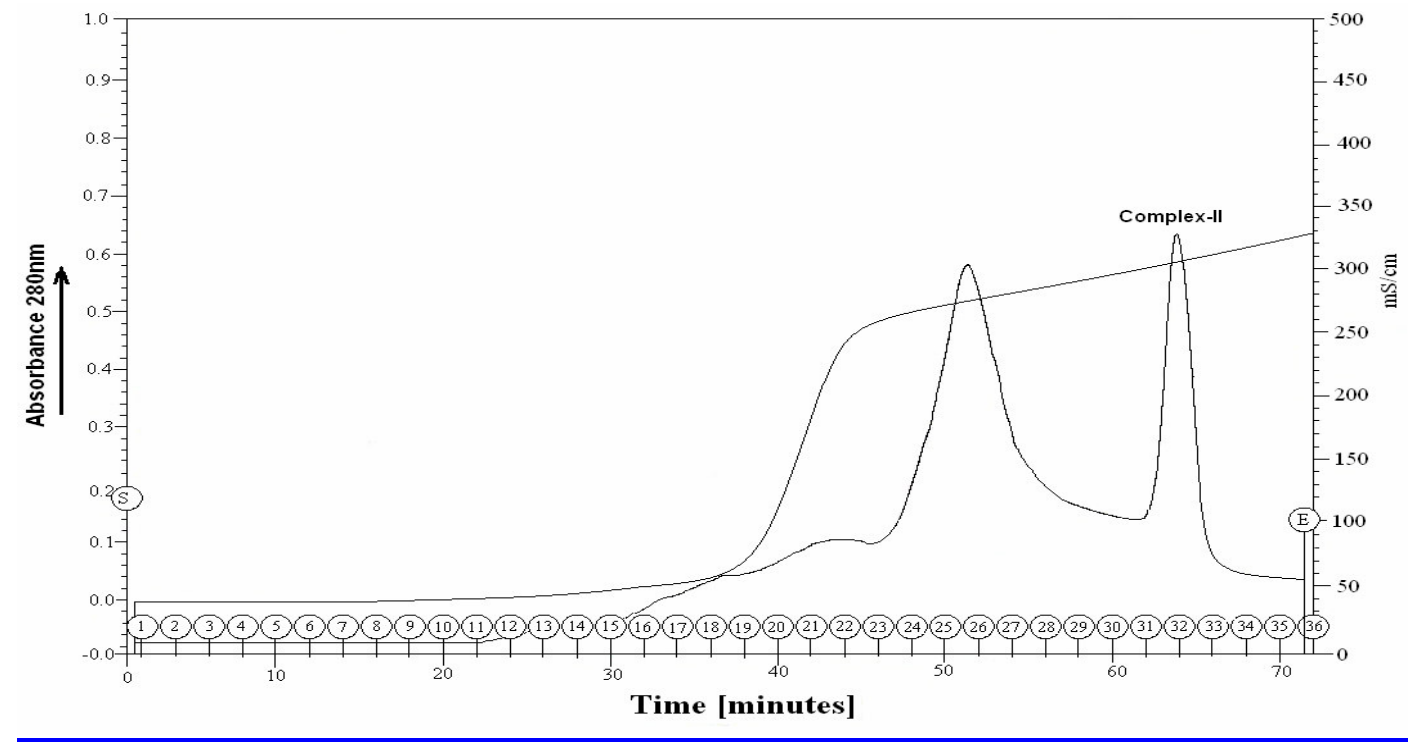

Figure 2. Anion exchange chromatography of complex II. The enzyme was eluted by using linear gradient solution of $600 \mathrm{ml}$ each of buffer A containing 1\% of Triton X-100 and buffer B containing 1\% Triton X-100 and $1.0 \mathrm{M} \mathrm{NaCl}$.

Table 1. Purification of complex II from Proteus mirabilis strain ATCC 29245

\begin{tabular}{cccccc}
\hline Step & $\begin{array}{c}\text { Total Vol. } \\
(\mathbf{m l})\end{array}$ & $\begin{array}{c}\text { Total Protein } \\
(\mathbf{m g})\end{array}$ & $\begin{array}{c}\text { Total heme b } \\
(\mathbf{n m o l})\end{array}$ & $\begin{array}{c}\text { Heme b protein } \\
\text { nmol/mg }\end{array}$ & Yield \% \\
\hline Solublized membranes & 80.0 & 235 & 310 & 1.3 & 100 \\
DEAE- Sephadex & 25.0 & 39 & 119 & 3.05 & 38.34 \\
DEAE- Bio Gel & 10.0 & 8.7 & 41.3 & 4.08 & 13.3 \\
Gel Filtration & 8.0 & 4.2 & 35.6 & 8.5 & 11.48 \\
Purified Enzyme & 1.0 & 2.9 & 27.4 & 9.5 & 8.7 \\
\hline
\end{tabular}

\section{Spectral properties of Complex II from Proteus mirabilis} ATCC 29245

Absorption spectrum of complex II is shown in the Figure 3. Figure $3 \mathrm{~A}$ showed the oxidized spectrum of the membrane proteins and showed a single absorption peak at $411.0 \mathrm{~nm}$. When the enzyme was reduced with the addition of sodium dithionite it showed peaks at 557, $524.8 \& 424 \mathrm{~nm}$ as shown in figure 3B. The characteristic $\alpha$-peak at $557 \mathrm{~nm}$ showed the presence of heme b. The figure 3C showed peaks at 556.8, $524.8 \& 420 \mathrm{~nm}$ of pyridine ferrohemochrome spectrum, which further confirmed the presence of cytochrome b in complex II.

\section{Polyacrylamide Gel Electrophoresis}

The purified enzyme was subjected to Native PAGE (7) followed by Coomassie brilliant blue and the heme staining. A single band showed that the enzyme was purified to homogeneity (Fig. 4).

Apparent molecular weights of proteins were estimated by polyacrylamide gel electrophoresis in the presence of SDS by the method of Laemmli (10). Purified sample of solubilized membrane proteins was loaded upon $12.5 \%$ SDS-PAGE along with a standard marker proteins ladder (Fig. 5). The sample showed prominent protein band in the region of 68.5, 29 and 
$19 \mathrm{kDa}$.

\section{Assay of Redox activity}

The enzymatic properties of the Proteus mirabilis succinate: quinone oxidoreductase was analyzed by using the artificial electron acceptor DCPIP. When succinate was added to the oxidized enzyme under aerobic conditions, the heme $b$ moiety of enzyme was fully reduced in 5 min (Fig.6) at 660nm.

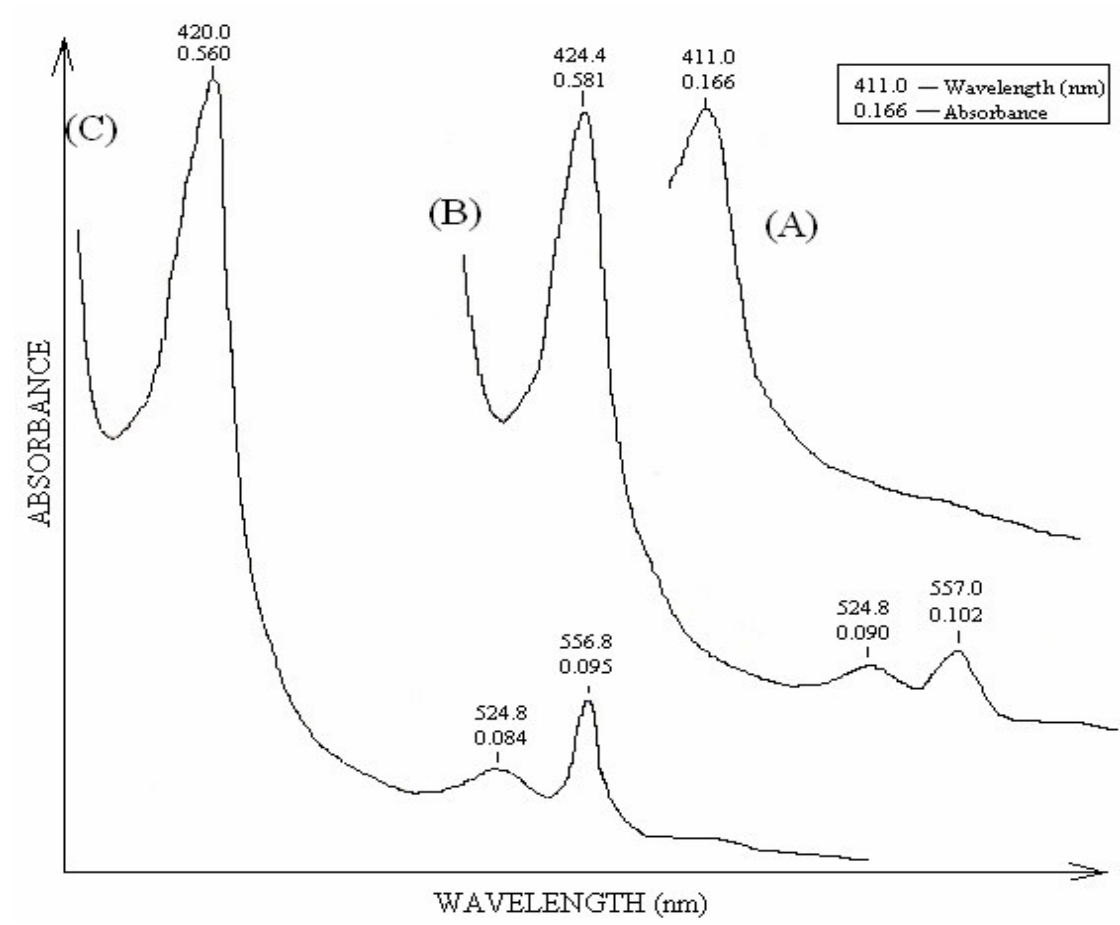

Figure 3. Spectral properties of the Proteus mirabilis strain ATCC 29245. Absorption spectra of cytochrome $b$ from Proteus mirabilis strain ATCC 29245 at room temperature. The cytochrome $b$ was suspended in $50 \mathrm{mM}$ tris- $\mathrm{HCl}(\mathrm{pH} 8.4)$ containing $1 \%$ Triton X-100. A: Oxidized absorption spectrum. The cytochrome $\mathrm{b}$ was oxidized by adding $1 \mathrm{M}$ potassium dichromate. B: Reduced spectrum of membrane-bound cytochrome b. The cytochrome b was reduced with sodium dithionite. C: Pyridine ferrohemochrome spectrum. The cytochrome $b$ was suspended in $0.2 \mathrm{~N} \mathrm{NaOH}$ and pyridine and reduced with a small amount of sodium dithionite.

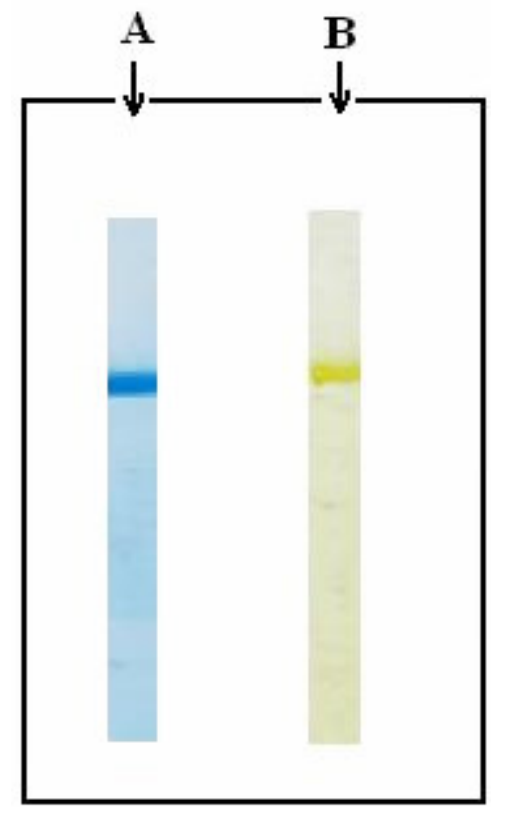

Figure 4. NATIVE PAGE of the Proteus mirabilis strain ATCC 29245. The purified cytochrome b was run on NATIVE PAGE and stained. Column A: Commassie brilliant blue staining of heme $b$, Column B: Heme Staining of heme b. 


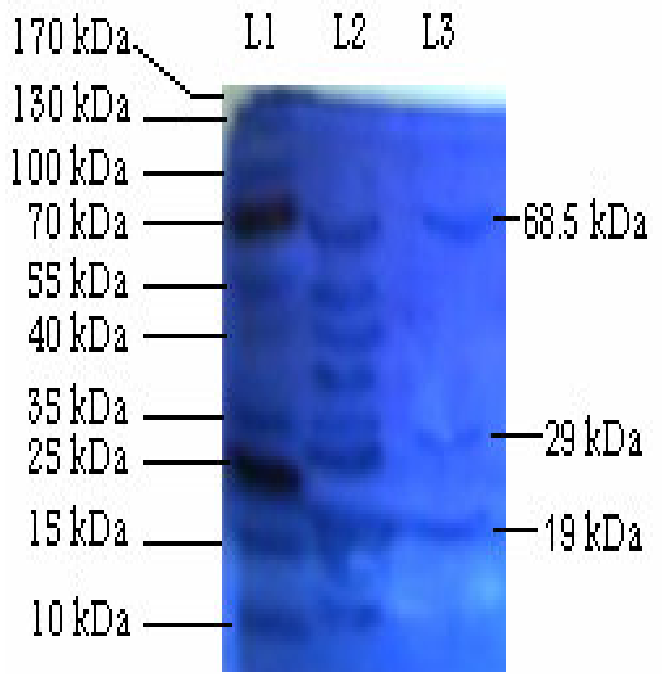

Figure 5. SDS-PAGE of the Proteus mirabilis strain ATCC 29245. The purified cytochrome b was loaded on $12.5 \%$ gel. The gel was stained with commassie brilliant blue after electrophoresis. Lane 1 (molecular mass marker proteins), lane 2 (sample 1, partially purified complex II after ion exchange chromatography) and lane 3, (sample 2, purified complex II). The molecular masses of three subunits of the Proteus mirabilis strain ATCC 29245 complex II were estimated to be 68, 28.5, and 19.5 $\mathrm{kDa}$.

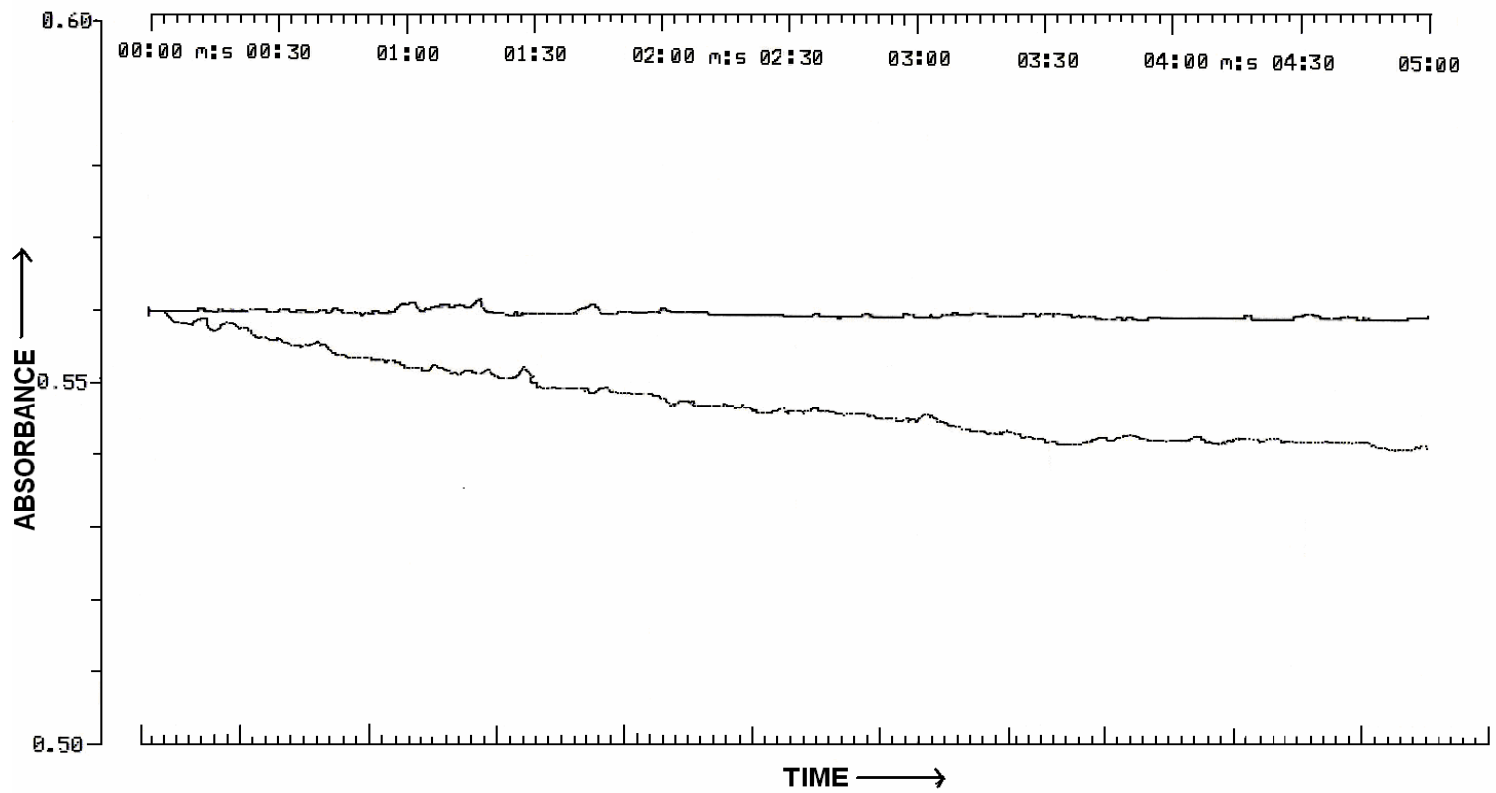

Figure 6. Enzyme assay of complex II from Proteus mirabilis strain ATCC 29245. The enzymatic reaction was time-scanned for $5 \mathrm{~min}$ at $660 \mathrm{~nm}$ to observe the decrease in absorption of DCPIP dye which acts as artificial electron acceptor in vitro.

\section{DISCUSSION}

Proteus mirabilis is a pathogenic microorganism so the study of its respiratory proteins is important. Growth profile of Proteus mirabilis was studied in shake flasks, incubated at $37^{\circ} \mathrm{C}$ at $250 \mathrm{rpm}$ (diameter $2.5 \mathrm{~cm}$ ). The culture was found to grow exponentially between 8-14 hours. Maximum biomass was accumulated after 12 hours as shown in Figure 1. Decline phase started after 14 hours was due to the exhaustion of nutrients and accumulation of toxic by-products particularly release of $\mathrm{H}_{2} \mathrm{~S}$ gas (23).

Cytochrome $\mathrm{b}$ is a component of Complex II and is required for electron transfer from succinate to ubiquinone (8). The $b$-type cytochromes in bacteria function as essential 
components of the respiratory complexes. The cytochrome b functions between two HQNO sites or more probably in a Qor b-cycle (22). Presence of succinate: quinone oxidoreductase and many types of cytochrome b of complex II present in bacterial electron transport chain have been reported and confirmed in Proteus mirabilis but its isolation from plasma membrane could not be achieved. In the present study, we have reported for the first time the isolation of cytochrome $b$ and succinate: quinone oxidoreductase in complex II from plasma membrane of Proteus mirabilis ATCC 29245. The nonionic detergent Triton $\mathrm{X}-100$ was found to be the best suitable detergent for solubilization and stabilization of cytochrome b and succinate: quinone oxidoreductase of this bacterium. The enzyme is stable in the presence of Triton X-
100 and has showed high succinate: quinone oxidoreductase activity. When the enzyme was oxidized with $\mathrm{K}_{2} \mathrm{Cr}_{2} \mathrm{O}_{7}$, the spectra showed that the Soret absorption peak at $411 \mathrm{~nm}$; upon reduction with sodium dithionite, the Soret absorption maxima shifted at $424 \mathrm{~nm}$ and the $\alpha$-absorption peak appeared at $557 \mathrm{~nm}$ while $\beta$-absorption peak appeared at $525 \mathrm{~nm}$ as shown in figure 3. These absorption peaks were attributed to the reduced form of cytochrome b and are very close to the values observed in isolated cytochrome $\mathrm{b}$ from other bacteria as given in Table 2 . The presence of single form of cytochrome $b$ is indicated by the symmetrical $\alpha$-absorption peak at $557 \mathrm{~nm}$ in reduced form. This result suggests that in the isolated complex II from Proteus mirabilis, only one type of cytochrome b is involved in electron transfer.

Table 2. Comparison of soluble cytochrome b-557 from different bacteria

\begin{tabular}{ccccc}
\hline Property & $\begin{array}{c}\text { P. mirabilis } \\
\text { Present Work }\end{array}$ & $\begin{array}{c}\text { B. subtilis } \\
\text { (Qureshi } \text { et al. 1996) (16) }\end{array}$ & $\begin{array}{c}\text { E. coli } \\
\text { (Yariv } \text { et al. 1981) (25) }\end{array}$ & $\begin{array}{c}\text { P. aerogenosa } \\
\text { (Moore } \text { et al. 1986) (13) }\end{array}$ \\
\hline $\begin{array}{c}\lambda \text {-max at } 25^{\circ} \mathrm{C} \\
(\text { Oxidized form) }\end{array}$ & $411 \mathrm{~nm}$ & $412 \mathrm{~nm}$ & $417 \mathrm{~nm}$ & 418 \\
$\lambda$-max at $25^{\circ} \mathrm{C}$ & $424.4,524.8,557$ & $425,526,556.5$ & $425,527,557$ & $424,526,557$ \\
$\left(\begin{array}{l}\text { Reduced form) } \\
\lambda \text {-max at } 25^{\circ} \mathrm{C}\end{array}\right.$ & $420,524.8,556.8$ & $420,526,556.5$ & N.A & N.A \\
$($ Pyridine spectra) & & & & \\
\hline
\end{tabular}

A prominent protein stained bands in the region of about $68.5,29$, and $19 \mathrm{kDa}$ of covalently bound succinate: quinone oxidoreductase in the membrane fraction of Proteus mirabilis appeared when the membrane proteins from Proteus mirabilis run on $12.5 \%$ SDS-PAGE along with standard marker proteins (Fig.5). The $19 \mathrm{kDa}$ subunit of complex II from the Proteus mirabilis strain ATCC 29245 stained with hemestaining reagent, considering that the succinate: quinone oxidoreductase seems to combine heme $b$ component in molecule which strongly suggests that the enzyme isolated with Triton X-100 maintains its intact structure.

Bacterial succinate: quinone oxidoreductase may have one or two hemes $b$ in the molecule. Spectral properties of the succinate: quinone oxidoreductase enzyme from Proteus mirabilis strain ATCC 29245 also suggests the presence of only one type of heme $\mathrm{b}$ in the molecule. On the basis of total heme $\mathrm{b}$ content, the recovery in the purification was calculated to be about $9.5 \mathrm{nmol} / \mathrm{mg}$ of heme $\mathrm{b}$, which yields $8.7 \%$ of the total solublized proteins. For further investigation and conformation of the presence of cytochrome $\mathrm{b}$ in Proteus mirabilis, energy-linked reduction of cytochrome $b$ has been studied when complex II is fully reduced with a substrate such as succinate. It is generally accepted that succinate: quinone oxidoreductase (Complex II) is a membrane bound respiratory complex and is associated with cytochrome b (24). The enzymatic properties of the Proteus mirablis succinate: quinone oxidoreductase was analyzed by using the artificial electron acceptor DCPIP. When sodium succinate (an electron donor) was added to the oxidized enzyme, the heme b moiety of the enzyme was almost fully reduced in $5 \mathrm{~min}$ with the 
decrease in absorbance of DCPIP dye .The overall activity was quite prominent and notable. It looks like; the succinate: quinone oxidoreductase enzyme in this bacterium is highly active.

In the present study we have found that the complex II of Proteus mirabilis strain ATCC 29245 has a single heme b in the molecule which was confirmed by spectroscopic studies.

\section{REFERENCES}

1. Ackrell, B.A. (2000). Progress in understanding structure-function relationships in respiratory chain complex II. FEBS. Lett., 466, 1-5.

2. Anraku, Y. (1988). Bacterial electron transport chains. Annu. Rev. Biochem., 57,101-132.

3. Connelly, J.L.; Morrison, M.; Stotz, E. (1958). Hemins of beef heart muscle. J. Biol. Chem., 233, 743-747.

4. Decaro, N.; Campolo, M.; Desario, C.; Cirone, F.; D'Abramo, M.; Lorusso, E.; Greco, G.; Mari, V.; Colaianni, M.L.; Elia, G.; Martella, V.; Buonavoglia, C. (2008). Respiratory disease associated with bovine coronavirus infection in cattle herds in Southern Italy. J. Vet. Diagn. Invest., 20, 28-32.

5. Goldberg, A.L.; Menon, A.S.; Goff, S.; Chin, D.T. (1987). The mechanism and regulation of the ATP-dependent protease La from Escherichia coli. Biochem. Soc. Trans., 15, 809-811.

6. Hagerhall, C.; Aasa, R.; Wachenfeldt, C.V.; Hederstedt, L. (1992). Two hemes in Bacillus subtilis succinate:menaquinone oxidoreductase (complex II). Biochemistry., 31, 7411-7421.

7. Hames, B.D.; Rickwood, R. (1989). Gel Electrophoresis of Proteins: A Laboratory Manual. IRL Press, NY.

8. Hirawake, H.; Taniwaki, M.; Tamura, A.; Kojima, S.; Kita, K. (1997). Cytochrome $\mathrm{b}$ in human complex II (succinate-ubiquinone oxidoreductase): cDNA cloning of the components in liver mitochondria and chromosome assignment of the genes for the large (SDHC) and small (SDHD) subunits to 1q21 and 11q23. Cytogenet. Cell Genet., 79, 132138.

9. Kita, K.; Vibet, C.R.T.; Meinhardt, S.; Guest, J.R.; Gennis, R.B. (1989). One step purification from Escherichia coli of complex II (succinate:ubiquinone oxidoreductase) associated with succinate reducible cytochrome b556. J. Biol. Chem., 264, 2672-2677.

10. Laemmli, U.K. (1970). Cleavage of Structural Proteins during the Assembly of the Head of Bacteriophage T4. Nature., 227, 680-685.

11. Lancaster, C.R.; Kröger, A. (2000). Succinate: quinone oxidoreductases: new insights from X-ray crystal structures. Biochim. Biophys. Acta., 1459, 422-431.

12. Lima, A.; Zunino, P.; D'Alessandro, B.; Piccini, C. (2007). An ironregulated outer-membrane protein of Proteus mirabilis is a haem receptor that plays an important role in urinary tract infection and in in vivo growth. J. Med. Microbiol., 56, 1600-1607.

13. Moore, G.R.; Mann, S.; Bannister, J.V. (1986). J. Inorg. Biochem., 28, 329-336.

14. O’Hara, C.M.; Brenner, F.W.; Miller, J.M. (2000). Classification, identification and clinical significance of Proteus, Providencia and Morganella. Clin. Microbiol. Rev., 13, 534-546.

15. Pennoyer, J.D.; Ohnishi, T.; Trumpower, L.B. (1988). Purification and properties of succinate-ubiquinone oxidoreductase complex from Paracoccus denitrificans. Biochim. Biophys. Acta., 935,195-205.

16. Qureshi, M.H.; Fujiwara, T.; Fukumori, Y. (1996). Succinate:Quinone Oxidoreductase (Complex II) Containing a Single Heme b in Facultative Alkaliphilic Bacillus sp. Strain YN-2000. J. Bacteriol., 178, 3031-3033.

17. Sambongi, Y.; Iko, Y.; Tanabe, M.; Omote, H.; Iwamoto-Kihara, A.; Ueda, I.; Yanagida, T.; Wada, Y.; Futai, M. (1999). Mechanical rotation of the c subunit oligomer in ATP synthase (FOF1): direct observation. Science., 286, 1722-1734.

18. Schagger, H.; von Jagow, G. (1987). Tricine-sodium dodecyl sulfatepolyacrylamide gel electrophoresis for the separation of proteins in the range from 1 to $100 \mathrm{kDa}$. Anal. Biochem., 166, 368-379.

19. Simon, C.B.; Stuart, J.F.; Bernd, L.M.; Dudley, P.; Oliver-Matthias, H.R.; Rob, J.M.; van Spanning. (1988). Molecular Genetics of the Genus Paracoccus: Metabolically Versatile Bacteria with Bioenergetic Flexibility. Microbiol. Mol. Biol. Rev., 62, 1046-1078.

20. Van Wielink, J.E.; Reijnders, W.N.; Oltmann, L.F.; Leeuwerik, F.J.; Stouthamer, A.H. (1983). The membrane-bound b and c-type cytochromes of Proteus mirabilis grown under different conditions. Characterization by means of coupled spectrum deconvolution and potentiometric analysis. Arch. Microbiol., 134, 118-122.

21. Van Wielink, J.E.; Reijnders, W.N.; Oltmann, L.F.; Stouthamer, A.H. (1983). Electron transport and cytochromes in aerobically grown Proteus mirabilis. Arch. Microbiol., 136, 152-157.

22. Van Wielink, J.E.; Reijnders, W.N.; Van Spanning, R.J.; Oltmann, L.F.; Stouthamer, A.H. (1986). The functional localization of cytochromes b in the respiratory chain of anaerobically grown Proteus mirabilis. Antonie. Van. Leeuwenhoek., 52,105-16.

23. Van Woert, M.H. (1967). Proteus mirabilis enterocolitis following abdominal irradiation. Report of a case. Am. J. Dig. Dis., 12, 737-741.

24. Waldeck, A.R.; Stowell, M.H.; Lee, H.K.; Hung, S.C.; Matsson, M.; Hederstedt, L.; Ackrell, B.A.; Chan, S.I. (1997). Electron paramagnetic resonance studies of succinate:ubiquinone oxidoreductase from Paracoccus denitrificans. Evidence for a magnetic interaction between the 3Fe-4S cluster and cytochrome b. J. Biol. Chem., 272, 19373- 19382.

25. Yariv, J.; Kalb, A.J.; Sperling, R.; Bauminger, E.R.; Cohen, S.G.; Ofer, S. (1981). J. Biol. Chem., 259, 112-123.

26. Zugravu, R.; Licker, M.; Berceanu-Văduva, D.; Rădulescu, M.; Adămuț, M.; Dragomirescu, L.; Branea, D.; Hogea, E.; Muntean, D.; Mihaela, D.P.; Moldovan, R.; Loredana, G.P. (2006). The establishment of 
resistance phenotypes for bacteria isolated from outpatients in urine cultures. Roum. Arch. Microbiol. Immunol., 65, 93-99.

27. Zunino, P.; Sosa, V.; Schlapp, G.; Allen, A.G.; Preston, A.; Maskell, D.J.
(2007). Mannose-resistant Proteus-like and P. mirabilis fimbriae have specific and additive roles in P. mirabilis urinary tract infections. FEMS. Immunol. Med. Microbiol., 51, 125-133. 